\title{
Legal Aspects of Tissue Banking
}

\author{
Ulrich M. Gassner \\ Faculty of Law, University of Augsburg, Augsburg, Germany
}

\section{Key Words}

Confidentiality $\cdot$ Commercialization $\cdot$ Human tissue sample $\cdot$ Informed consent $\cdot$ Legal aspects $\cdot$ Regulatory safeguards · Tissue banking • Biobanks

\begin{abstract}
There exists no clear national or international consensus in key issues of tissue banking. This holds especially true for the fundamental concept of informed consent. During recent years, the harmonization of norms needed for international collaboration has made crucial progress solely in Europe, namely through legal framing. The norms relating to tissue banking are, however, under permanent construction not only in Europe but throughout the world. Consequently, anybody involved in tissue banking is well advised to observe the evolution of the legal and regulatory environment in the particular jurisdiction.

Copyright $\odot 2007$ S. Karger AG, Basel
\end{abstract}

\section{Introduction}

The collection and banking of human tissue is on the rise throughout the world. Tissue banking implicates a variety of ethical concerns pertaining to such values as dignity, bodily integrity, autonomy, and privacy. These ethical concerns have been translated into a complex and incoherent apparatus of private and public, national and international standards and provisions. This apparatus embraces, e.g., UNESCO's International Declaration on Human Genetic Data (2003), the Recommendation $\operatorname{Rec}(2006) 4$ of the Committee of Ministers of the Council of Europe (COE) to Member States on research on biological materials of human origin (2006), the FDA final rule 'Human Cells, Tissues, and Cellular and TissueBased Products; Establishment Registration and Listing' (2001), the European Human Tissue Directive 2004/23/ EC (2004), the standards of the American Association of Tissue Banking (ATAB), the guidelines of the Swiss Academy of Medical Sciences (2006) as well as several national laws such as the Swedish Act on Biobanks (2002). All these norms differ not only with respect to their effect of being legally binding but also reveal that there is no clear national or international consensus in pivotal issues of tissue banking. There is not even a generally accepted definition of tissue banks yet. The Swedish Act on Biobanks, e.g., defines the term 'biobank' rather narrowly as 'biological material from one or several human beings collected and stored indefinitely or for a specified time and whose origin can be traced to the human or humans from whom it originates', whereas, according to the more recent European Human Tissue Directive, the generic term 'tissue establishment' means a tissue bank or a unit of a hospital or another body where activities of processing, preservation, storage or distribution of human tissues and cells are undertaken'. As a rule, tissue banks are not perceived as being conceptionally restricted to research purposes.

This concise survey aims at highlighting the range of legal and non-legal ramifications of tissue banking relevant to four main factors: (1) commercialization, (2) confidentiality, (3) informed consent, and (4) regulatory safeguards. These four factors are often considered to be reflective of some of the major ethical issues that arise in the conduct of tissue banking research.

\section{KARGER}

Fax +4161306 1234

E-Mail karger@karger.ch

www.karger.com
(C) 2007 S. Karger AG, Basel

1015-2008/07/0744-0270\$23.50/0

Accessible online at:

www.karger.com/pat
Ulrich M. Gassner

Faculty of Law, University of Augsburg

Postfach, DE-86135 Augsburg (Germany)

Tel. +49821 598 4590, Fax +49821 5984591

E-Mail ulrich.gassner@jura.uni-augsburg.de 


\section{Commercialization}

Commercial biobanks are attempting to position themselves as a, if not the, solution to problems that include a lack of public trust in researchers and lack of financial resources to support the prospective creation of collections that meet the highest scientific and ethical standards in the non-profit sector [1]. Perhaps the most important benefit associated with commercial biobanks and tissue banks stem from the successful interchange between the two spheres of industry and academia, toward a more efficient transmission of knowledge from academic-based tissue banks to industry, boosting the development and delivery of medical products to the public. There is, however, a potential downside of the commercialization of tissues. The likelihood of conflicts of interest is increased insofar as, e.g., financial incentives to academic researchers could undermine scientific standards of integrity. Beyond this concern, commercial tissue banking gives rise to a plethora of broader cultural, religious, social, and psychological issues on the treatment of the human body and its parts [2]. As a consequence, views of legislators, authorities and non-governmental organizations on the acceptability of commercial biobanks vary to a substantial extent [3].

Several regulations therefore suggest some discomfort with the idea of profit from the mere transfer or exchange of human tissue. The European Human Tissue Directive which has been legally binding since April 2006 provides that Member States shall endeavor to ensure donations of tissues and cells are unpaid and that the procurement of tissues and cells as such is carried out on a non-profit basis. Donors may only receive compensation which is strictly limited to making good the expenses and inconveniences related to the donation. The principle that human biological materials should not, as such, give rise to financial gain is also set out in the Additional Protocol to the COE Convention on Human Rights and Biomedicine (CHRB), on Transplantation of Organs and Tissues of Human Origin (2002). Further details on the prohibition of profits can be found in the Explanatory Report to the Additional Protocol. It is stated there that organs and tissues should not be bought or sold or give rise to direct financial gain for the person from whom they have been removed for a third party. Nor should the person from whom they have been removed, or a third party, gain any other advantage whatsoever comparable to a financial gain such as benefits in kind or promotion for example. A third party involved in the transplant process such as a health professional or a tissue bank may not make a profit from organs or tissues or any products developed from them. Payments which do not constitute a financial gain or a comparable advantage shall, however, not be prevented, in particular: compensation of living donors for loss of earnings and any other justifiable expenses caused by the removal or by the related medical examinations; payment of a justifiable fee for legitimate medical or related technical services rendered in connection with transplantation; compensation in case of undue damage resulting from the removal of organs or tissues from living persons. The more recent Recommendation of the Committee of Ministers of the Council of Europe on research on biological materials of human origin follows the same restrictive approach. In the case of the donor it allows only for compensation for loss of earnings and other justifiable expenses. According to the explanatory memorandum to this recommendation the prohibition of financial gain should not prevent payments for legitimate scientific or technical services rendered in connection with the use of such biological materials. Such acts might include the cost of retrieval, transport, preparation, preservation and storage of organs or tissues, which may legitimately give rise to reasonable remuneration. The problem with this kind of approach is that it ignores that academic-industry relationships may be beneficial for spurring innovative research [3].

A slightly more liberal concept of commercialization is realized in the UK Human Tissue Act (2004). The Act provides several exceptions from the general prohibition of commercial dealings in human material for transplantation set out there. It allows, in addition, for costs incurred by others to be passed along a chain of suppliers, provides that it is not an offence to provide expenses or recompense for loss of earnings given to an individual supplying human material and allows for the possibility of commercial tissue banks by allowing license-holders to receive more than just expenses in relation to these activities. It remains to be seen, however, if the words 'as such' and the somewhat ambiguous wording of the other pertinent provisions of the Human Tissue Directive may serve as a loophole for EU Member States to interpret the prohibition of financial gain narrower as it seems to be feasible at first sight.

As opposed to the situation in Europe, US federal law allows fees for the recovering, processing and transporting of human tissue. Beyond that regulation there are only two agency reports that provide guidelines addressing some minor important aspects of commercial tissue banking [1,3]. All in all, commercialization 'as such' seems not to be perceived as a real problem in the USA. 


\section{Confidentiality}

Confidentiality or data protection refers to the promise not to disclose information that the donor does not want to be disclosed. It is common ground that there is a taxonomy of different protection levels ranging from 'identified' to 'anonymous'. The European Human Tissue Directive, e.g., addresses a certain degree of confidentiality by providing that 'Member States shall take all necessary measures to ensure that all data, including genetic information, collated within the scope of this Directive and to which third parties have access, have been rendered anonymous so that neither donors nor recipients remain identifiable'. It also requires adoption of all the measures necessary to ensure that the identity of recipients is not disclosed to donors and/or their families, and vice versa, without prejudice to the provisions in force in Member States on conditions for disclosure. The Human Tissue Directive itself offers, however, no clear guidance on the requested level of anonymization. It contains merely a generalized reference to the European Data Protection Directive 95/46 which defines that 'an identifiable person is one who can be identified, directly or indirectly, in particular by reference to an identification number or to one or more factors specific to his physical, physiological, mental, economic, cultural or social identity'. To determine whether a person is identifiable, account should be taken, according to the Directive, of all likely reasonable means. This means that an individual shall not be regarded as 'identifiable' if identification requires an unreasonable amount of time or manpower.

The terminology used by the European Council documents cited above is also based on this concept of identifiability. The recent Recommendation of the Committee of Ministers to Member States on research on biological materials of human origin differentiates, at least implicitly, between five levels of anonymization for human samples: 'anonymous', 'unlinked anonymized', 'linked anonymized', 'coded', and 'identified'. Anonymity is achieved when no means are available to link data to an identifiable individual. Samples containing any trace of DNA are not truly anonymous, because it is always possible to identify the donor through DNA fingerprinting [4]. 'Anonymous' is therefore considered by commentators an appropriate term only for archaeological samples [5]. The counterpart term 'identified' implies that the information that allows identification such as the donor's name is associated directly with the tissue sample.

The three other levels of anonymization are explicitly addressed within the concept of identifiability. Biological materials are classified in two categories: identifiable biological materials and non-identifiable biological materials. The Recommendation of the Committee of Ministers specifies that 'identifiable biological materials' refers to those materials that 'alone or in combination with associated data, allow the identification of the persons concerned either directly or through the use of a code'. In the latter case, they are referred to as 'coded' materials when researchers and users have access to the code, and as 'linked anonymized' materials when they not have access to the code, which is under the control of a third party. 'Non-identifiable biological materials' are referred to as 'unlinked anonymized' biological materials, i.e., those materials that, 'alone or in combination with associated data do not allow, with reasonable efforts, the identification of persons concerned'. According to the explanatory memorandum to the Recommendation, unlinked anonymized biological materials and data are materials and data from which all identifiers have been removed. While they may not allow for the identification of a specific individual as any associated information is irrevocably deleted, they may allow the identification of a group of individuals.

Whereas in European documents, the term 'anonymized' could mean either 'unlinked' or 'linked anonymized', in most US and English Canadian texts, 'anonymized' refers only to 'unlinked anonymized' samples. Furthermore, according to the European terminology, 'coded' always means that researchers or other users have access to the code. The US Office for Human Research Protections (OHRP) takes another view on this term and uses it in its Guidance on Research Involving Coded Private Information or Biological Specimens (2004) to refer to what Europeans and French Canadians call 'linked anonymized' samples, implying that the code is not accessible to third persons [5]. These discrepancies are not the only examples for what has been rightly called 'the Babel of genetic data terminology' [6]. As mentioned earlier, coded and linked anonymized samples are considered to be identifiable in Europe, because in both cases a link exists. Samples and data are considered unidentifiable only if this link is irreversibly destroyed. The OHRP, however, enlarged the definition of non-identifiable in its Guidance as follows: 'OHRP considers private information or specimens not to be individually identifiable when they cannot be linked to specific individuals by the investigator(s) either directly or indirectly through coding systems.' This shall be the case if, in addition, 'the investigators and the holder of the key enter into an agreement prohibiting the release of the key to the investigators un- 
der any circumstances, until the individuals are deceased'. It follows that researchers are provided with a simple means to define themselves if tissue samples are identifiable or not identifiable [5].

\section{Informed Consent}

The discrepancies described above are not limited to different definitions of the same term, but even more seriously, involve the idea of informed consent, often correctly called the gold standard of research ethics [7]. The consequence of enlarging the definition of non-identifiable is obvious: As any research using non-identifiable samples does not create an obligation to obtain informed consent, US researchers can escape from the need for consent simply by entering agreements that prohibit them from access to the code. This 'American solution' [5] is, at least in a formal sense, in line with the World Medical Association (WMA) Declaration of Helsinki: Ethical Principles for Medical Research Involving Human Subjects (2004), which states that 'Medical research involving human subjects includes research on identifiable human material or identifiable data'. The broad definition of 'non-identifiable' is used as a loophole to escape the informed consent concept that is most often recommended in the USA and Canada, i.e., the so-called multilayered consent, which asks research participants to make different choices on a detailed form. In general there is a tendency to achieve limited consent, related to one disease or to a specific future research project [5].

European policy follows a somewhat more lenient standard of informed consent. The European Data Protection Directive defines data subject's consent as 'any freely given specific and informed indication of his wishes by which the data subject signifies his agreement to personal data relating to him being processed'. This might require some specificity but the degree is not clear. The Human Tissue Directive offers even less guidance by only stating that 'The procurement of human tissues or cells shall be authorized only after all mandatory consent or authorisation requirements in force in the Member State concerned have been met'. More precise is the Recommendation of the Committee of Ministers which enunciates that consent or authorisation to obtain biological materials for research 'should be as specific as possible with regard to any foreseen research uses and the choices available in that respect'. It follows from the proviso of possibility that general or broad consent, although distinguished from blanket consent, would be considered sufficient as regards un- foreseen future research uses. Otherwise tissue banks would be virtually unsuitable for their purpose. The approach of limiting the principle of restriction to a specific purpose is also implied in the explanatory memorandum to the Recommendation of the Committee of Ministers: 'When biological materials of human origin and personal data are collected it is best practice to ask the sources for their consent to future use, even in cases where the specifics of the future research projects are unknown.' The concept of general consent is endorsed by several European guidelines such as the statement of the German National Ethics Council (2004) where it is said that 'it must be made possible for donors to consent to the use of their samples and data for undefined research projects to be specified only at some future date'. The same holds true for the Guideline on Biobanks of the Swiss Academy of Medical Sciences in which general consent is established as a rule for research purposes.

It has to be stressed that this 'European solution' abandons the classical concept of informed consent [5]. The phenomenon of establishing a less strict standard for future, as yet unspecified research projects is, however, not confined to Europe. Some Asian guidelines take a similar view. The Bioethics Committee of the Japanese Council for Science and Technology, e.g., promotes in its report on 'Fundamental Principles of Research in the Human Genome' the idea of 'comprehensive consent' (2000): 'If a participant consents to provide a research sample for genome analysis in a particular research project and, at the same time, anticipates and consents to the use of the same sample in other genome analyses or related medical research, then the research sample may be used for the latter "studies aimed at other purposes".'

This and other types of general consent are often considered valid only if general information requirements are met. According to the Annex of the European Human Tissue Directive, the information must cover 'the purpose and nature of the procurement, its consequences and risks; analytical tests, if they are performed; recording and protection of donor data, medical confidentiality; therapeutic purpose and potential benefits and information on the applicable safeguards intended to protect the donor'. Prominent examples of these safeguards are the donors' right to withdraw samples at any time, often also called 'opt out', including destruction of their sample and to know any information collected about his or her health. Furthermore, the Recommendation of the Committee of Ministers sets out the institutional requirement that a future research project should only be undertaken if it has been subject to an independent examination of its scien- 
tific merit and ethical acceptability. Thus, the consequences of the 'European solution' are mitigated by procedural and institutional safeguards.

\section{Regulatory Safeguards}

A plethora of additional regulatory safeguards and requirements is to be observed. In the US, tissue establishments are required to screen and test donors, to prepare and follow written procedures for the prevention of the spread of communicable disease, and to maintain records. Since 2001, FDA has published three final rules to broaden the scope of products subject to regulation and to include more comprehensive requirements to prevent the introduction, transmission and spread of communicable disease. One final rule requires tissue processing facilities to register and list their human cell, tissue, and cellular and tissue-based product (HCT/Ps) with FDA. In its Federal Register notice of 1998, FDA states several goals shall be achieved by this regulation, with the primary objective being 'the improved protection of the public health without the imposition of unnecessary restrictions on research, development, or the availability of new products'. The second rule requires tissue establishments to evaluate donors, through screening and testing, to reduce the transmission of infectious diseases through tissue transplantation. The third final rule establishes current good tissue practices for HCT/Ps.

The most recent European Human Tissue Directive 2004/23/EC contains a similar, but more comprehensive approach. It provides, in addition, that EU Member States should establish an accreditation system for tissue establishments and a system for notification of adverse events and reactions linked to the procurement, testing, processing, preservation, storage and distribution of human tissues and cells and organize inspections and control measures, to ensure that tissue establishments comply with the provisions of this Directive. The issue of oversight is also addressed in the Recommendation of the Committee of Ministers but, interestingly, limited only to population biobanks.

\section{Conclusions and Outlook}

The opaque legal and regulatory landscape of tissue banking has often evoked the call for an international harmonization of policies regarding this subject matter $[1,3,5]$. Although the only way to achieve future progress in tissue banking seems to be through harmonization of the key terms and the key norms, developing a roadmap for getting there is rather difficult for several reasons [8]. The more recent development provides little hope in this respect. There exists a lack of international consensus even in the fundamental concept of informed consent. Thus, regional and national norms will gain more importance. Primarily in Europe, remarkable legal and regulatory efforts have been made on $\mathrm{COE}$ and EC level during the last few years. This development has not reached its peak yet and will continue with, e.g., the transposition of the European Human Tissue Directive into national law which will be accompanied by further guidance such as the proposed EMEA Guideline on Biobanks Issues Relevant to Pharmacogenetics. Another example for the process of further juridification, i.e., legal framing, of tissue banking is the draft of the Swiss Research on Humans Act which will be based on a constitutional amendment. Thus, the framework of norms relating to tissue banking is under permanent construction. As a consequence, anybody involved in various aspects of tissue banking is well advised to be cognizant of the evolution of the legal and regulatory environment impacting his or her activities in the particular jurisdiction.

\section{References}

1 Anderlik M: Commercial biobanks and genetic research: ethical and legal issues. Am J Pharmacogenomics 2003;3:203-215.

-2 Nelkin D, Andrews L: Homo economicus: the commercialization of body tissue in the age of biotechnology. Hastings Cent Rep 1998; 28:30-39.
Bauer K, Taub S, Parsi K: Ethical issues in tissue banking for research: a brief review of existing organizational policies. Theor Med Bioeth 2004;25:113-142.

$\checkmark 4$ Lin Z, Owen AB, Altman RB: Genomic research and human subject privacy. Science 2004;305:183.

5 Elger BS, Caplan AL: Consent and anonymization in research involving biobanks. EMBO Rep 2006;7:661-665.
Knoppers BM, Saginur M: The Babel of genetic data terminology. Nat Biotechnol 2005; 23:925-927.

7 Kegley JA: Challenges to informed consent. EMBO Rep 2004;5:832-836.

8 Maschke KJ, Murray TH: Ethical issues in tissue banking for research: the prospects and pitfalls of setting international standards. Theor Med Bioeth 2004;25:143-155. 